\title{
Effects of advance regeneration and germinated seedlings on forest recovery after clearcutting of Chamaecyparis obtusa plantations in Southern Kyushu, Southwestern Japan
}

\author{
Kazuhiro Yamashita ${ }^{1,4} \cdot$ Hiromi Yamagawa $^{2} \cdot$ Hiroki Kondo $^{3,5} \cdot$ Satoshi Ito $^{3} \cdot$ Ryoko Hirata $^{3}$
}

Received: 7 July 2021 / Revised: 16 September 2021 / Accepted: 4 October 2021 / Published online: 23 October 2021

(c) The Author(s) 2021

\begin{abstract}
We clarified the effect of advance regeneration on natural forest recovery after clearcutting of conifer plantations over the mid-term observation period (12-14 years to allow formation of the forest canopy). We established understory-intact plot (UI-plot), where advance regeneration (AR; DBH more than $1 \mathrm{~cm}$ before clearcutting) were retained, and understory-cleared plot (UC-plot), where all ARs were removed at felling of conifer crops. We surveyed individual density, species richness, and tree height with reference to different regeneration origins 1 year after and 12 or 14 years after clearcutting. Then, we compared the structural changes in UI-plot with that in UC-plot. The resprouted AR in UC-plot has provided the same effect as the retained AR in UI-plot in forming their height distribution patterns and stratification over a mid-term recovery process. We also found that individual density and species richness attributed by the individuals of newly established seedlings after clearcutting (SE), have contributed to the stand development in the both plots. Furthermore, SE was found to have a large contribution to forest recovery in terms of tree density and species number, while its significance for the recovery of gravity-dispersal, lucidophyllous trees was limited. We concluded that the advantage of AR retention is limited to the fast recovery of forest structure at the early stage after clearcutting, and mostly disappeared over a mid-term observation period as far as abundant advance regeneration was sufficiently accumulated and surrounding seed sources were effectively secured.
\end{abstract}

Keywords Forest recovery $\cdot$ Retained advance regenerations $\cdot$ Seedling $\cdot$ Seed source $\cdot$ Species diversity

\section{Introduction}

After the Montreal Process, the implementation of Sustainable Forest Management has been emphasized to promote forestry productivity and the conservation of biodiversity through appropriate ecosystem management (Nagaike

Satoshi Ito

s.ito@cc.miyazaki-u.ac.jp

1 Interdisciplinary Graduate School of Agriculture and Engineering, University of Miyazaki, Miyazaki, Japan

2 Kyushu Research Center, Forestry and Forest Products Research Institute, Kumamoto, Japan

3 Faculty of Agriculture, University of Miyazaki, 1-1, Gakuen-kibanadai-nishi, Miyazaki 889-2192, Japan

4 Present Address: Japan International Forestry Promotion and Cooperation Center (JIFPRO), Tokyo, Japan

5 Present Address: Kinki-Chugoku Regional Forest Office, Forest Agency, Osaka, Japan
2000; Eycott et al. 2006; Yamagawa et al. 2008, 2013; Ramirez-Collio et al. 2017). In Japan, conifer plantations have increased due to extensive afforestation after WWII. These plantation areas include numerous sites inappropriate for planting forestry, and forest management has been abandoned in some plantations due to a decline in timber prices. To restore the ecosystem services and increase biodiversity in these areas, as well as realize sustainable forest management goals, forest restoration through integrating natural regeneration is considered necessary (Zerbe 2002; Ito et al. 2013; Onaindia et al. 2013; Yamagawa et al. 2013; Brown et al. 2015).

Natural regeneration has been shown to be important for the recovery of semi-natural forests after the clearcutting of plantations. Of the various regeneration methods, the use of advance regeneration, buried seeds, and dispersed seeds have all been demonstrated to plays important roles in forest recovery (Yamagawa et al. 2010b, 2013). Over the short-term, advance regeneration contributes to forest recovery and the generation of semi-natural forests in a warm-temperate region 
in Japan (Yamagawa et al. 2008). However, the growth conditions required for advance regeneration are markedly affected by land-use history, forest stand age, forest type, and related factors (Yamagawa et al. 2010b). In addition, advance regeneration is a hindrance for timber operations in plantations, which are often cleared. It has also been demonstrated that a dependence on the sources of regeneration, such as advance regeneration and resprouting, can simplify the species composition during forest recovery and reduce species diversity (McLaren and McDonald 2003; Ito et al. 2008).

Based on a quantitative survey of regenerated individuals 1 year after clearcutting Chamaecyparis obtusa plantations, Yamagawa et al. (2008) reported that leaving advance regeneration contributes to forest recovery in the short-term and maintains diversity of "lucidophyllous tree" species those are the components of the lucidophyllous forests, the evergreen broadleaved forests characteristically found in warm-temperate monsoon Asia (Hattori et al. 2004, 2009). Specifically, Yamagawa et al. (2008) showed that leaving individuals when clearcutting provides a source of regeneration that exceeds the contribution of sprouting individuals after clearing. However, short-term assessments of early regeneration do not consider longer term forest dynamics, such as subsequent disturbances, competition between individuals, and recruitment of seedlings. For this reason, the contribution of advance regeneration may be reduced over longer term observations.

In this study, we surveyed the survival and growth of broad-leaved trees 1 year after clearcutting and 12-14 years after clearcutting in C. obtusa stands in the same plot used by Yamagawa et al. (2008) to evaluate the role of different regeneration origins over a mid-term observational period which would allow formation of forest canopy. The study stand was treated by retaining or clearing the advance regeneration, and compared stand structure, individual density, species richness, and tree height class distribution between plots. Using these surveys, we investigated the contribution of retaining the advance regeneration to natural forest recovery. The specific objectives of this study were to clarify (1) whether retaining the advance regenerations contributes to forest recovery after clearcuttig over a mid-term observational period than the resprouting advance regenerations, and (2) whether the advance regenerations and the resprouting advance regenerations contribute to forest recovery, especially of lucidophyllous tree species than seedlings.

\section{Methods}

\section{Study site}

The study was conducted in two clear-cut plantation stands of C. obtusa at the Tano Forest Science Station (experimental forest) of the University of Miyazaki located in southern Kyushu, southwestern Japan. The forest stands were situated in the lowlands (approximately 110-300 m a.s.l.) of a warm temperate region within a lucidophyllous forest dominated by Fagaceae and Lauraceae species (Miyawaki 1981). The mean annual temperature and mean annual precipitation over the past 10 years were $17.5^{\circ} \mathrm{C}$ and $2500 \mathrm{~mm}$, respectively. There was no obvious influence or damages by sika deer on the vegetation found in the study site at our investigation periods.

\section{Experimental treatment}

In this study, we classified the regeneration sources into two types; advance regeneration before clearcutting (AR) which have diameter at breast height (DBH; $1.3 \mathrm{~m}$ height) of more than $1 \mathrm{~cm}$, and newly established seedlings (SE) (Fig. 1). Then, AR were further classified into two subcategories: those survived through logging (survived AR: S-AR), and those cut and resprouted after logging (resprouted AR: R-AR).

Two survey plots of different treatments on AR were used in this study. The first was a plot in which the understory was retained intact with AR at the time of felling the overstory layer of C. obtusa ("understory-intact" plot: UI-plot). The second was a plot in which the understory brush was cleared, including the AR, at the time of felling the overstory layer of C. obtusa ("understory-cleared" plot: UC-plot). The UI-plot was established in a 90-year-old C. obtusa stand in 2005, while the UC-plot was established in an 80-yearold $C$. obtusa stand in 2003. Understory vegetation, such as advance regeneration, was relatively abundant prior to felling in both plots. The plot area of the understory-intact treatment (UI-plot) and that of the understory-cleared treatment (UC-plot) was $950 \mathrm{~m}^{2}$ and $825 \mathrm{~m}^{2}$, respectively. The UI-plot was located near an 83-year-old C. obtusa plantation (2.7 ha, $7 \mathrm{~m}$ apart from plot) which consisted of several broadleaved trees in the canopy layer. The UC-plot was located near a 90-year-old broadleaf-mixed C. obtusa plantation (4 ha, $6 \mathrm{~m}$ apart from plot) and a 101-year-old evergreen broadleaved forest (6.1 ha, $35 \mathrm{~m}$ apart from plot).

\section{Field survey}

Before clearcutting of the C. obtusa stands in August 2005 at the UI-plot and in October 2003 at the UC-plot, species, tree locations, DBH, and tree heights of all AR individuals were noted in each plot. Trees were identified with a number tag. Coniferous trees and liana species were not surveyed.

Immediately after felling $C$. obtusa stands at the UI-plot in December 2005 and at the UC-plot in May 2004, tag numbers of surviving advance regeneration (S-AR) were recorded. For safety reasons during felling at the UI-plot, 


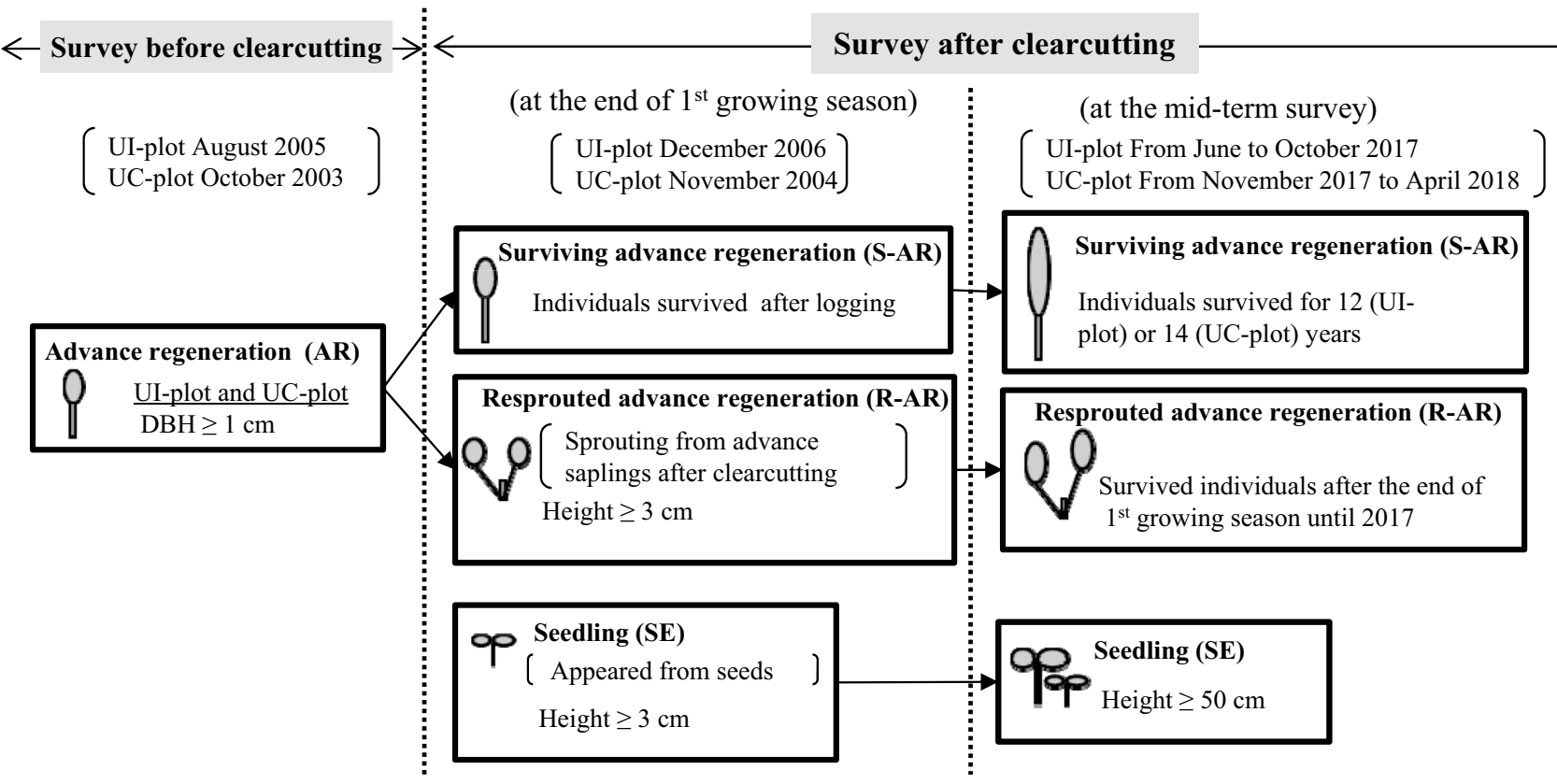

Fig. 1 Diagram of time schedule and method of surveying individuals before and after clearcutting. UI-plot and UC-plot denote understoryintact plot and understory-cleared plot, respectively. $D B H$ diameter at breast height

some of AR was cleared. Thus, the tag numbers of surviving advance regeneration trees were recorded. In contrast, all AR in the UC-plot was removed, and S-AR individual was not found.

One year after clearcutting the C. obtusa stands at the UI-plot in December 2006 and at the UC-plot in November 2004, tree species, tree locations, DBH, and tree heights were recorded for S-AR, resprouted advance regeneration (R-AR) more than $3 \mathrm{~cm}$ in height, and broadleaved tree seedlings germinated after felling (SE) more than $3 \mathrm{~cm}$ in height (Fig. 1).

After 12 years at the UI-plot from June to October 2017, and after 14 years at the UC-plot from November 2017 to April 2018, we measured DBH and tree heights for S-AR, R-AR taller than $50 \mathrm{~cm}$, and $S E$ taller than $50 \mathrm{~cm}$.

$\mathrm{S}-\mathrm{AR}$ and R-AR were collectively referred to as the advance regeneration group (ARG).

\section{Data analysis}

Individual trees in the study plots were classified into tree species groups with reference to the characteristic habitats and seed dispersal types, as well as regeneration origins (SE, S-AR and R-AR). The shifts in individual densities, species richness, and the distributions of tree height class were then determined for each classification type. On the basis of their the characteristic (original) habitats and the life forms, we classified tree species into five groups
(Yamagawa et al. 2008) as follows: (1) "pioneer species", (2) "coppice woodland shrubs", (3) "coppice woodland trees", (4) "lucidophyllous shrubs", and (5) "lucidophyllous trees". Coppice woodland shrubs and trees occur in frequently disturbed forests, such as coppice woodlands, but are not typical pioneer species (Yamagawa et al. 2008). Lucidophyllous shrubs and trees are known to inhabits in well-developed lucidophyllous forests rather than in disturbed forests (Yamagawa et al. 2008). The dominant species in the survey conducted in 2017 were Mallotus japonicus and Fagara ailanthoides, which are pioneer species; Callicarpa mollis and Premna microphylla, which are coppice woodland shrubs; Ehretia ovalifolia and Morus australis, which are coppice woodland trees; Eurya japonica and Maesa japonica, which are lucidophyllous shrubs; and Cinnamomum camphora and Castanopsis spp., which are lucidophyllous trees (Table S1). Furthermore, the types of seed dispersal, i.e., wind-, frugivore-, and gravity-dispersal, were classified. These groups and dispersal types were classified with reference to previous studies (Kitamura and Murata 1979; Okuda 1997; Mogi et al. 2000).

Ratios of individual densities and species richness for regenerated sources (advance regeneration group (ARG) and seedlings (SE)) and seed dispersal types (frugivoreand gravity-dispersal types) were analyzed by Fisher's exact test. Statistical analyses were conducted using $\mathrm{R}$ (v. 3.3.0; R Core Team 2016). 


\section{Results}

\section{Stand structure}

Table 1 shows the individual densities, species richness, and tree height for each tree species group at the UI-plot and UC-plot. At both plots, the dominant species group in terms of individual density in the first year after clearcutting was pioneer species, followed by lucidophyllous shrubs and lucidophyllous trees (Table 1). In 2017, the individual density of pioneer species decreased markedly at both plots, whereas individual densities of lucidophyllous shrubs and lucidophyllous trees decreased slightly (UI-plot) or increased (UCplot) (Table 1). The decline of the pioneer species densities was mainly due to the decrease in seedlings (SE) (Table S1).

The total species richness at each plot was almost unchanged between the first year and 2017 (Table 1). Pioneer species decreased from 18 species in 2006 to 10 species in 2017 at UI-plot and 17 species in 2004 to 14 species in 2017 at UC-plot. The species richness of lucidophyllous trees increased at both plots.

The mean tree height in 2006 at UI-plot and in 2004 at UC-plot were less than $1 \mathrm{~m}$ for all species groups (Table 1). However, the tree height of lucidophyllous trees at UI-plot in 2006 was higher than that at UC-plot in $2004(0.8 \mathrm{~m}$ and $0.4 \mathrm{~m}$, respectively). In 2017, the height of lucidophyllous trees were almost same between the two plots.

\section{Individual density for the different regeneration origins and seed dispersal types}

Table 2 shows the individual densities for the different regeneration origins for all tree species and lucidophyllous tree species at the UI-plot and the UC-plot. At the UI-plot, most of the S-AR and R-AR in all species in 2006 survived until 2017 (Table 2a). Similarly, at the UC-plot, more than $80 \%$ of R-AR found in 2004 have also survived until 2017 (Table 2a). Values of the ARG density slightly decreased both in UI-plot (2810/ha in 2006 to 2411/ha in 2017) and in UC-plot (3830/ha in 2004 to 3164/ha in 2017) (Table 2a). SE remarkably decreased their number (down to $22 \%$ of 2006 in UI-plot and 39\% of 2004 in UC-plot) in the both plots by 2017 , but were still higher than ARG at both plots (Table 2a). The ratios of ARG to total densities increased until 2017 compared to the first year after clearcutting at both plots (from 5.7 to $18.7 \%$ in UI-plot, and from 8.5 to $16.3 \%$ in UC-plot, respectively; $p<0.001)$ by the decrease of SE densities.

For lucidophyllous tree species, the densities of ARG and SE in 2017 did not differ markedly or were almost same compared to those in 2006 or 2004 (Table 2a). SE of lucidophyllous tree species decreased from 4832 to $2926 /$ ha in UI-plot, but were maintained as $60 \%$ of the initial value. In UC-plot, SE of lucidophyllous tree species increased from 1988 to 2303/ha (Table 2a).

For the difference in the individual densities by seed dispersal types, in both all species and lucidophyllous species, the density of gravity-dispersal-type in ARG slightly decreased but maintained $90 \%$ of 2006 in UC-plot and 77\% of 2004 in UI-plot (Table 2b). For SE in all species and in lucidophyllous species, most of them were the frugivoredispersal-type in the both plots in the both censuses (the first year after clearcutting and 2017). In all species, the density of gravity-dispersal-type SE increased in the both plots (242/ha to 716 /ha in UI-plot and 909/ha to 1188 /ha in UC-plot), but were still lower compared to that of ARG (Table 2b). Similar trends were found in lucidophyllous tree species in the both plots. The ratios of gravity-dispersal-type SE to total densities (0.5-2.9\%) were far lower than those of ARG (22.3-26.9\%) at both plots during each census $(p<0.001)$.

Table 1 Individual density (no/ha), species richness, and average tree height of each species group in the understory-intact plot and the understory-cleared plot

\begin{tabular}{|c|c|c|c|c|c|c|c|c|c|c|c|c|}
\hline \multirow[t]{3}{*}{ Species groups } & \multicolumn{6}{|c|}{ Understory-intact plot } & \multicolumn{6}{|c|}{ Understory-cleared plot } \\
\hline & \multicolumn{2}{|c|}{ Individual density (no./ha) } & \multicolumn{2}{|c|}{$\begin{array}{l}\text { Species rich- } \\
\text { ness }\end{array}$} & \multicolumn{2}{|c|}{$\begin{array}{l}\text { Average tree } \\
\text { height }(m)\end{array}$} & \multicolumn{2}{|c|}{ Individual density (no./ha) } & \multicolumn{2}{|c|}{$\begin{array}{l}\text { Species rich- } \\
\text { ness }\end{array}$} & \multicolumn{2}{|c|}{$\begin{array}{l}\text { Average tree } \\
\text { height }(m)\end{array}$} \\
\hline & 2006 & 2017 & 2006 & 2017 & 2006 & 2017 & 2004 & 2017 & 2004 & 2017 & 2004 & 2017 \\
\hline Pioneer & $26,653(54.0)$ & $1600(12.4)$ & 18 & 10 & 0.2 & 4.5 & $31,382(69.6)$ & $3648(18.9)$ & 17 & 14 & 0.2 & 5.2 \\
\hline Coppice woodland shrub & $3589(7.3)$ & $1653(12.8)$ & 13 & 7 & 0.2 & 2.0 & $1224(2.7)$ & $1224(6.3)$ & 5 & 5 & 0.2 & 2.1 \\
\hline Coppice woodland tree & $5295(10.7)$ & $632(4.9)$ & 4 & 10 & 0.2 & 4.4 & $1697(3.8)$ & $1236(6.4)$ & 11 & 13 & 0.2 & 4.6 \\
\hline Lucidophyllous shrub & $7411(15.0)$ & $4632(36.0)$ & 11 & 13 & 0.4 & 1.8 & $6618(14.7)$ & $9103(47.2)$ & 13 & 12 & 0.3 & 1.6 \\
\hline Lucidophyllous tree & $6389(12.9)$ & $4358(33.8)$ & 24 & 28 & 0.8 & 4.4 & $4158(9.2)$ & $4073(21.1)$ & 23 & 24 & 0.4 & 4.7 \\
\hline Total & 49,337 & 12,875 & 70 & 68 & 0.3 & 3.2 & 45,079 & 19,285 & 69 & 68 & 0.2 & 3.1 \\
\hline
\end{tabular}

Figures in parentheses denote the ratio $(\%)$ of the densities of each species group to total densities 
Table 2 Individual density (no/ha) of each (a) regenerated origin and each (b) seed dispersal type for all species and lucidophyllous tree species at each plot in different years

\begin{tabular}{|c|c|c|c|c|c|c|c|c|}
\hline \multirow{3}{*}{$\begin{array}{l}\text { (a) Regenerated } \\
\text { Origins }\end{array}$} & \multicolumn{4}{|c|}{ All species } & \multicolumn{4}{|c|}{ Lucidophyllous tree species } \\
\hline & \multicolumn{2}{|c|}{ Understory-intact plot } & \multicolumn{2}{|c|}{ Understory-cleared plot } & \multicolumn{2}{|c|}{ Understory-intact plot } & \multicolumn{2}{|c|}{$\begin{array}{l}\text { Understory-cleared } \\
\text { plot }\end{array}$} \\
\hline & 2006 & 2017 & 2004 & 2017 & 2006 & 2017 & 2004 & 2017 \\
\hline ARG & 2810 & 2411 & 3830 & 3164 & 1558 & 1431 & 2170 & 1770 \\
\hline S-AR & 1789 & 1579 & 0 & 0 & 947 & 884 & 0 & 0 \\
\hline R-AR & 1021 & 832 & 3830 & 3164 & 611 & 547 & 2170 & 1770 \\
\hline SE & 46,526 & 10,463 & 41,248 & 16,121 & 4832 & 2926 & 1988 & 2303 \\
\hline Total & 49,337 & 12,875 & 45,079 & 19,285 & 6389 & 4358 & 4158 & 4073 \\
\hline \multirow{3}{*}{$\begin{array}{l}\text { (b) Seed dispersal } \\
\text { types }\end{array}$} & \multicolumn{4}{|c|}{ All species } & \multicolumn{4}{|c|}{ Lucidophyllous tree species } \\
\hline & \multicolumn{2}{|c|}{ Understory-intact plot } & \multicolumn{2}{|c|}{ Understory-cleared plot } & \multicolumn{2}{|c|}{ Understory-intact plot } & \multicolumn{2}{|c|}{$\begin{array}{l}\text { Understory-cleared } \\
\text { plot }\end{array}$} \\
\hline & 2006 & 2017 & 2004 & 2017 & 2006 & 2017 & 2004 & 2017 \\
\hline \multicolumn{9}{|l|}{ ARG } \\
\hline Wind & 0 & 0 & 12 & 12 & 0 & 0 & 0 & 0 \\
\hline Gravity & 1095 & 989 & 1564 & 1188 & 1084 & 979 & 1564 & 1188 \\
\hline Frugivore & 1716 & 1421 & 2255 & 1964 & 474 & 453 & 606 & 582 \\
\hline \multicolumn{9}{|l|}{ SE } \\
\hline Wind & 53 & 0 & 679 & 182 & 0 & 0 & 0 & 0 \\
\hline Gravity & 242 & 716 & 909 & 1188 & 242 & 684 & 897 & 1152 \\
\hline Frugivore & 46,232 & 9747 & 39,661 & 14,752 & 4589 & 2242 & 1091 & 1152 \\
\hline Total & 49,337 & 12,875 & 45,079 & 19,285 & 6389 & 4358 & 4158 & 4073 \\
\hline
\end{tabular}

$A R G$ advance regeneration group, $S$ - $A R$ surviving advance regenerations, $R$ - $A R$ resprouted advance regenerations, $S E$ seedlings

\section{Species richness for the different regeneration origins and seed dispersal types}

Table 3 shows the difference in the species richness for the different regeneration origins and seed dispersal types for all tree species and lucidophyllous tree species at the UI-plot and the UC-plot. At the UI-plot, the species richness of ARG in 2006 was 36 species and many of these were counted in S-AR (35 species) (Table 3a). In 2017, out of the same 36 species in ARG, 34 were counted for S-RA. Species richness of SE in UI-plot were larger than that of ARG in the both censuses (57 and 63 species in 2006 and 2017, respectively). The ratios of species richness derived from ARG to the total species richness were $51.4 \%$ in 2006 and $52.9 \%$ in 2017 , which was less than that of SE (81.4\% in 2006 and $92.6 \%$ in 2017) $(p<0.001$, Table 3a).

At the UC-plot, 31 R-AR species were observed in 2004, and decreased to 28 species in 2017 (Table 3a). The ratios of species number of SE to total species were higher than those counted for ARG in both 2004 and $2017(p<0.001)$.

For lucidophyllous tree species, ARG at the UI-plot accounted for $83.3 \%$ of total species in 2006, which was not significantly different from that of SE (54.2\%) $(p=0.060)$; no significant difference was also observed in 2017 ( $p=0.177)$, though SE raised their contribution up to $89.3 \%$ (Table $3 \mathrm{a}$ ). At the UC-plot, the ratios of species richness in ARG and in the SE to the total species were 71-88\% during study period (Table $3 a$ ).

The species richness of the gravity-dispersed species in ARG at the UI-plot was 6 species in 2006, which was two species more than that of SE (4 species) (Table $3 b$ ). For the frugivore-dispersed species, a total of 63 species were observed at the UI-plot in 2006 and 52 species were in SE, which was 1.7 times that of the ARG (30 species). Similar seed-dispersal-type compositions were found at the UI-plot in 2017 and at the UC-plot in 2004 and 2017 (Table 3b).

For lucidophyllous tree species, the species richness of frugivore-dispersed species was higher for ARG (15) than SE (9) at the UI-plot in 2006 (Table 3b). However, no difference was observed in 2017 due to the increase in SE species (19). At the UC-plot, the species richness of frugivore-dispersed species in ARG was similar to that of SE throughout the study period (Table $3 b$ ). Species richness of gravity-dispersed SE increased by 1-2 species in each plot (Tables 3b, S1). 
Table 3 Species richness of (a) each regenerated origin and (b) seed dispersal type for all species and lucidophyllous tree species at each plot in different years

\begin{tabular}{|c|c|c|c|c|c|c|c|c|}
\hline \multirow{3}{*}{$\begin{array}{l}\text { (a) Regenerated } \\
\text { origins }\end{array}$} & \multicolumn{4}{|l|}{ All species } & \multicolumn{4}{|c|}{ Lucidophyllous tree species } \\
\hline & \multicolumn{2}{|c|}{ Understory-intact plot } & \multicolumn{2}{|c|}{ Understory-cleared plot } & \multicolumn{2}{|c|}{ Understory-intact plot } & \multicolumn{2}{|c|}{ Understory-cleared plot } \\
\hline & 2006 & 2017 & 2004 & 2017 & 2006 & 2017 & 2004 & 2017 \\
\hline ARG & $36(51.4)^{\mathrm{b}}$ & $36(52.9)^{\mathrm{b}}$ & $31(44.9)^{\mathrm{b}}$ & $28(41.2)^{\mathrm{b}}$ & $20(83.3)^{\mathrm{a}}$ & $20(71.4)^{\mathrm{a}}$ & $19(82.6)^{\mathrm{a}}$ & $17(70.8)^{\mathrm{a}}$ \\
\hline S-AR & $35(50.0)$ & $34(50.0)$ & - & - & $19(79.2)$ & $18(64.3)$ & - & - \\
\hline R-AR & $17(24.3)$ & $15(22.1)$ & $31(44.9)$ & $28(41.2)$ & $10(41.7)$ & $10(35.7)$ & $19(82.6)$ & $17(70.8)$ \\
\hline SE & $57(81.4)^{\mathrm{a}}$ & $63(92.6)^{\mathrm{a}}$ & $62(89.9)^{\mathrm{a}}$ & $64(64.1)^{\mathrm{a}}$ & $13(54.2)^{\mathrm{a}}$ & $25(89.3)^{\mathrm{a}}$ & $17(73.9)^{\mathrm{a}}$ & $21(87.5)^{\mathrm{a}}$ \\
\hline Total & 70 & 68 & 69 & 68 & 24 & 28 & 23 & 24 \\
\hline \multirow{3}{*}{$\begin{array}{l}\text { (b) Seed disper- } \\
\text { sal types }\end{array}$} & \multicolumn{4}{|l|}{ All species } & \multicolumn{4}{|c|}{ Lucidophyllous tree species } \\
\hline & \multicolumn{2}{|c|}{ Understory-intact plot } & \multicolumn{2}{|c|}{ Understory-cleared plot } & \multicolumn{2}{|c|}{ Understory-intact plot } & \multicolumn{2}{|c|}{ Understory-cleared plot } \\
\hline & 2006 & 2017 & 2004 & 2017 & 2006 & 2017 & 2004 & 2017 \\
\hline ARG & 36 & 36 & 31 & 28 & 20 & 20 & 19 & 17 \\
\hline Wind & $0(0)$ & $0(0)$ & $1(3.2)$ & $1(3.6)$ & $0(0)$ & $0(0)$ & $0(0)$ & $0(0)$ \\
\hline Gravity & $6(16.7)$ & $6(16.7)$ & $6(19.4)$ & $6(21.4)$ & $5(25.0)$ & $5(25.0)$ & $6(31.6)$ & $6(35.3)$ \\
\hline Frugivore & $30(83.3)$ & $30(83.3)$ & $24(77.4)$ & $21(70.5)$ & $15(75.0)$ & $15(75.0)$ & $13(68.4)$ & $11(64.7)$ \\
\hline SE & 57 & 63 & 62 & 64 & 13 & 25 & 17 & 21 \\
\hline Wind & $1(1.8)$ & $0(0)$ & $2(3.2)$ & $2(3.1)$ & $0(0)$ & $0(0)$ & $0(0)$ & $0(0)$ \\
\hline Gravity & $4(7.0)$ & 8 (12.7) & $5(8.1)$ & $6(9.4)$ & $4(30.8)$ & $6(24.0)$ & $4(23.5)$ & $5(23.8)$ \\
\hline Frugivore & $52(91.2)$ & $55(87.3)$ & $55(88.7)$ & $56(87.5)$ & $9(69.2)$ & $19(76.0)$ & $13(76.5)$ & $16(76.2)$ \\
\hline Total & 70 & 68 & 69 & 68 & 24 & 28 & 23 & 24 \\
\hline
\end{tabular}

Figures in parentheses denote the ratio (\%) of species number of each regenerated origin or seed dispersal type to total species number. The difference in the ratios of ARG and SE were analyzed by Fisher's exact test. Different letters indicate significant difference $(p<0.05)$

$A R G$ advance regeneration group, $S$ - $A R$ surviving advance regeneration, $R$ - $A R$ resprouted advance regeneration, $S E$ seedlings

\section{Tree height}

In all species, the UI-plot had a wider range of tree height distribution than that in the UC-plot in the first year after clearcutting (Fig. 2). Most S-AR in UI-plot were the 1-5 m height class and some reached the tree height class of $19 \mathrm{~m}$ in 2006 (Fig. 2a), while most R-AR in UC-plot only reached up to the 1-2 m height class in 2004 (Fig. 2b). In 2017, the height distribution of R-AR in the UC-plot was almost same as that of A-SR in the UI-plot (Fig. 2b).

For SE, almost all of the individuals occupied the $1 \mathrm{~m}$ height class in both plots at the first year after clearcutting (Fig. 3a, b). However, in 2017, these individuals showed a right-skewed distribution in the both plots. Majority of SE were less than $4 \mathrm{~m}$ in their height, but some of them reached 13-14 $\mathrm{m}$ in the both plot (Fig. 3a, b).

In the lucidophyllous trees, the tree height distributions of individuals in the ARG and SE were similar to the distribution in all tree species at both plots during the study periods (Figs. 4 and 5).

\section{Discussion}

\section{Mid-term significance of retaining advance regeneration (AR)}

This study examined the role of advance regenerations and newly recruited seedlings of broadleaved trees in the mid-term forest recovery after clearcutting of conifer plantations. At the end of the first year after clearcutting, as reported in the previous study (Yamagawa et al. 2008), the advance regeneration (AR) retained through the logging practice played an important role in successful early establishment of broadleaved trees. This was particularly apparent in the tree height distribution; the understoryintact plot (UI-plot), where most of ARs had been retained had a wider range of tree height than that in the understory-cleared plot (UC-plot), where all ARs had been removed (Figs. 2 and 4). This resulted in a partly wellretained stratification by the surviving advance regeneration (S-AR) in the UI-plot even immediately after logging 
(a) Understory-intact plot

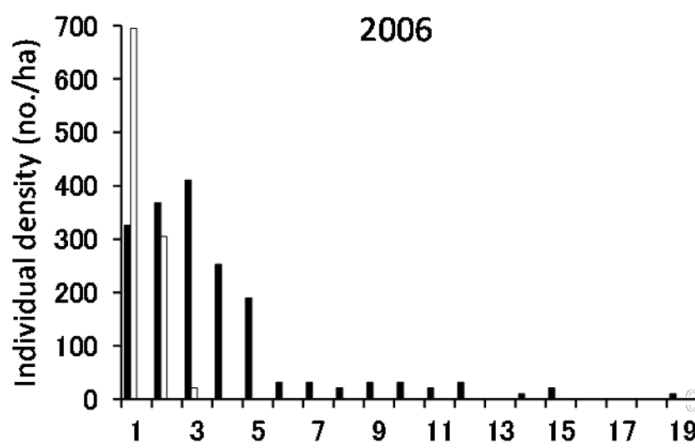

(b) Understory-cleared plot
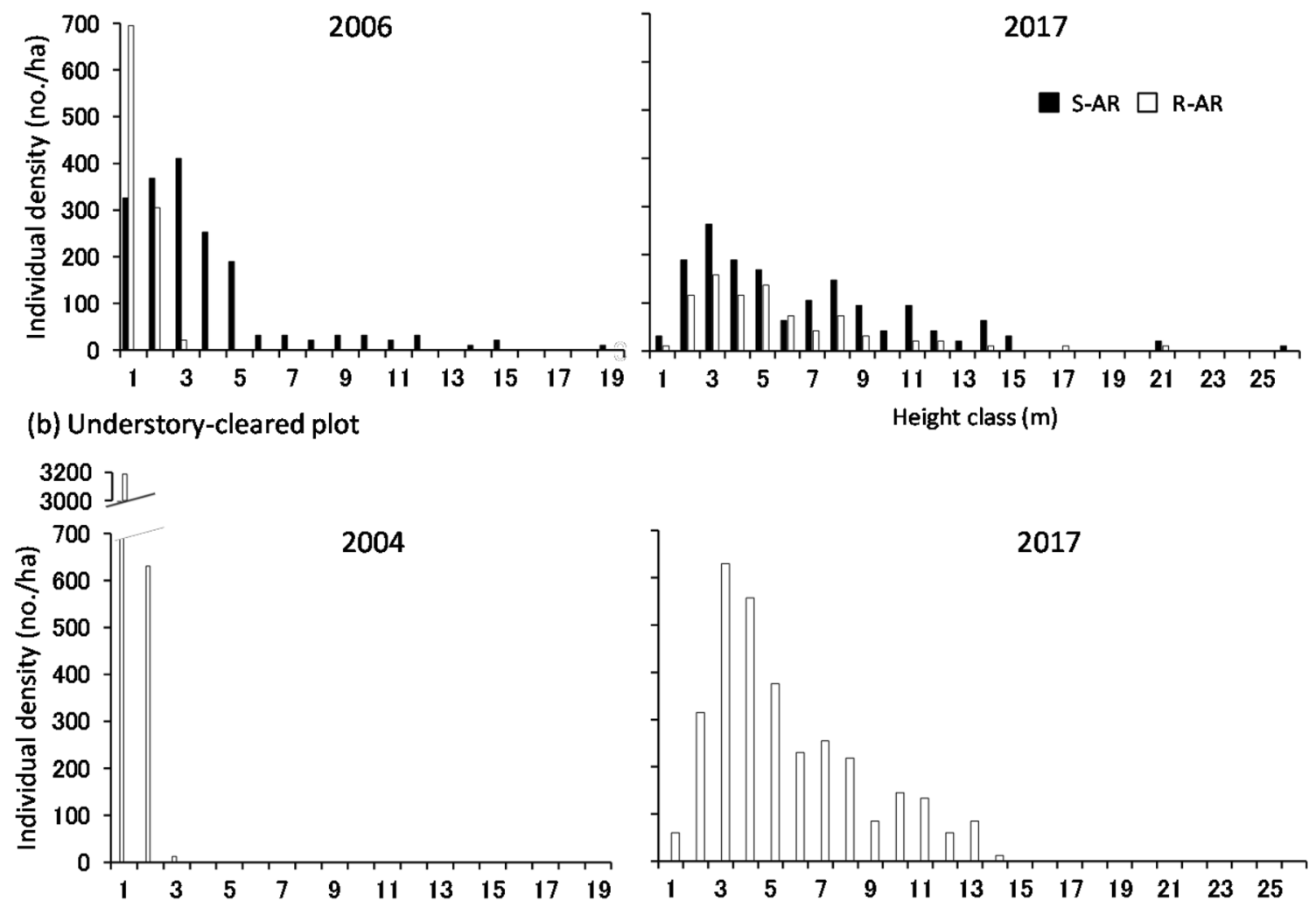

Height class (m)

Fig. 2 Tree height class distribution of regeneration origins in all species in $\mathbf{a}$ understory-intact and $\mathbf{b}$ understory-cleared plots. $S$ - $A R$ surviving advance regenerations, $R$ - $A R$ resprouted advance regenerations

(a) Understory-intact plot

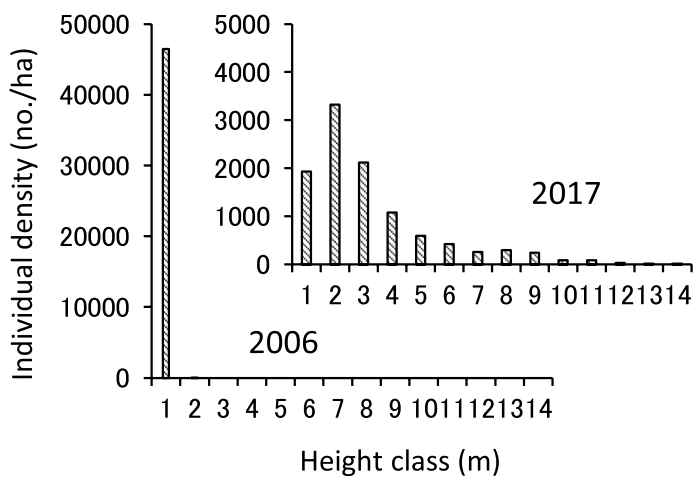

(b) Understory-cleared plot

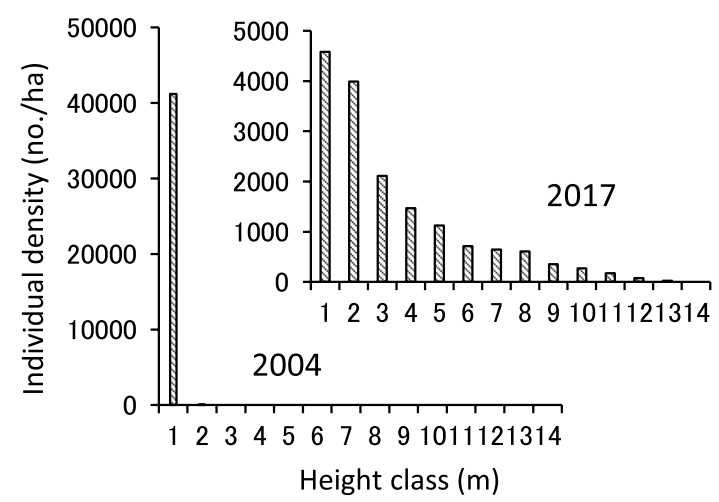

Fig. 3 Tree height class distribution of seedlings of all species in $\mathbf{a}$ the understory-intact plot and $\mathbf{b}$ the understory-cleared plot

of conifer crops. Yoshida (2019) also reported the similar results in other cases.

However, in contrast to these previous studies, in the present study conducted 12-14 years after clearcutting, the advantage of retaining AR in the UI-plot was not clearly observed over a mid-term forest recovery. In 2017, the height range of the resprouted advance regeneration (R-AR) in the UC-plot was almost same as that of S-AR in the UIplot (Figs. 2 and 4). This indicated that the contribution of R-AR to the height distribution and stratification has largely increased by their survival and vigorous growth during 14 years. Furthermore, in 2017, seedlings established after 
(a) Understory-intact plot
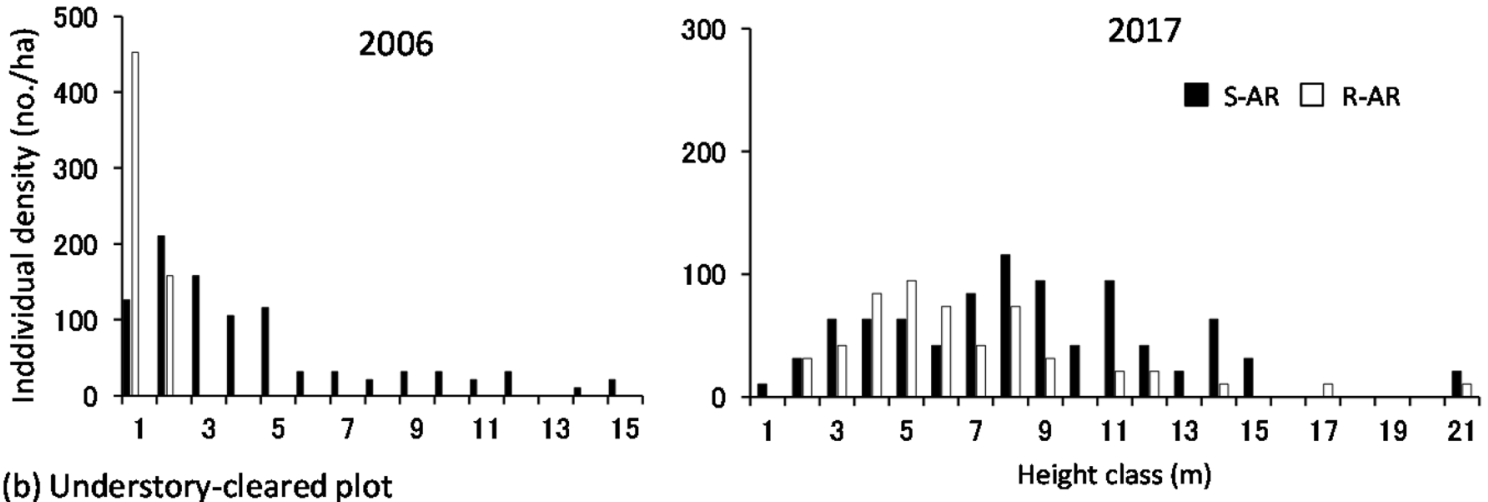

(b) Understory-cleared plot
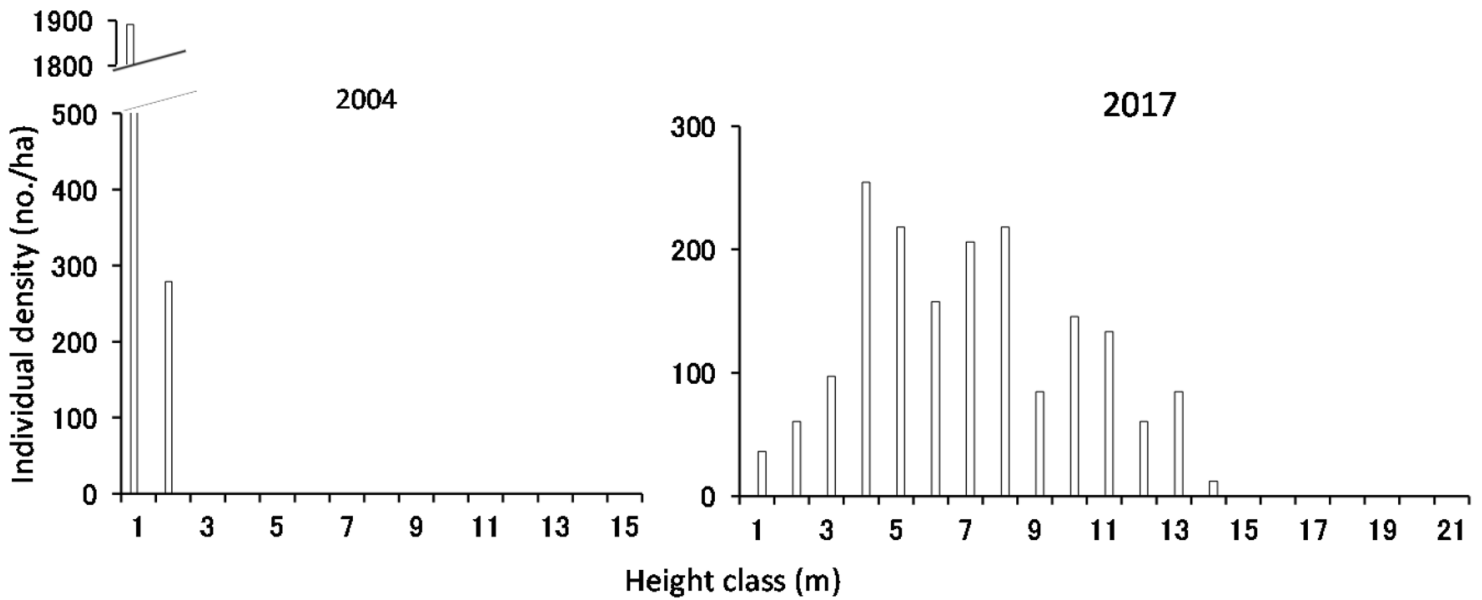

Fig. 4 Tree height class distribution of advance regeneration group in lucidophyllous tree species in $\mathbf{a}$ understory-intact plot and $\mathbf{b}$ understorycleared plot. $S$ - $A R$ surviving advance regenerations, $R$ - $A R$ resprouted advance regenerations

(a) Understory-intact plot

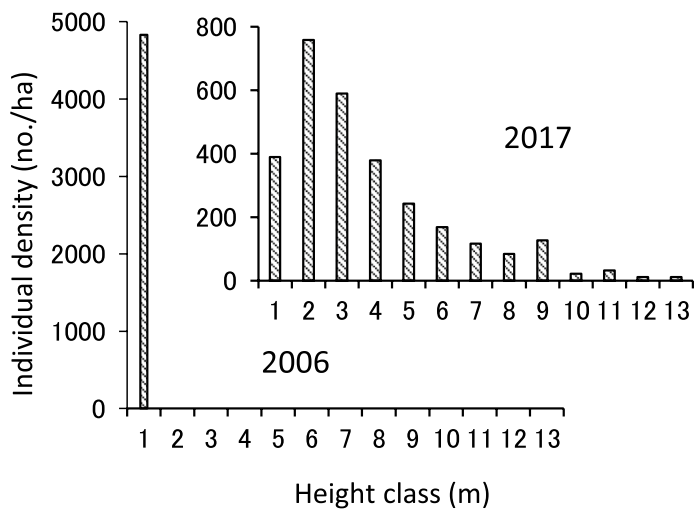

(b) Understory-cleared plot

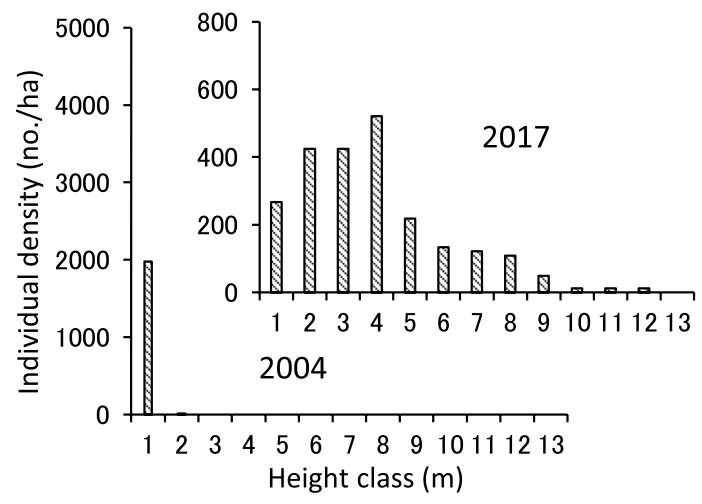

Fig. 5 Tree-height class distribution of seedlings of lucidophyllous tree species in a understory-intact plot and $\mathbf{b}$ understory-cleared plot

clearcutting (SE) also contributed to the development of height distribution in the both plots (Figs. 3 and 5); a majority of SE in 2017 were still less than $4 \mathrm{~m}$ in their height, but those reached $14 \mathrm{~m}$ were also observed. Thus, over the midterm forest recovery, SE together with R-AR, have developed the stand structure of the UC-plot as equivalent to that of the 
UI-plot. We could also observe a few tall S-AR individuals (15-25 $\mathrm{m}$ in height) (Figs. 2 and 4). However, it is rather reasonable to interpret these results that the advantage of retaining AR has mostly disappeared over a mid-term forest recovery.

Regarding the individual density (Table 2), S-AR did not decrease their individual number largely, and maintained their role in forest recovery until 2017 . However, more than $80 \%$ of R-AR in the UC-plots have also survived and contributed to forest recovery. The remarkable decrease of R-AR was not observed even in the UI-plot, where shorter R-AR at the first year were expected to suffer from a possible suppression by the canopy of taller S-AR. These trends for the all species were also same for lucidophyllous trees (Table 2). SE remarkably decreased their number in the both plots by 2017 , but maintained the density of lucidophyllous trees which was same or more compared to those by ARG (S-AR and R-AR). These results suggested that, in 2017, recovered forest structure in the UC-plot were attributed significantly by individuals of SE and R-AR that compensated the lack of S-AR.

Species number, another important measures of forest recovery, was almost same irrespective of retaining/ removing AR at the first year after clearcutting (Table 3); in the UC-plot, R-AR compensated the species number, and this did not change in 2017. For the all species (Table 3a), though R-AR decreased their species number slightly (2-3 species), SE compensated this decline in the both plots. Number of lucidophyllous species also showed the similar trend (Table 3a).

These results of tree density and species number would suggest that retained AR did not promote mid-term merit in forest recovery, and thus the advantage of AR retention was limited to the fast recovery of forest structure at the early stage after clearcutting as far as many ARs before logging and surrounding seed source after logging are sufficiently secured.

\section{Contribution of seedlings established after clearcutting (SE)}

In the mid-term forest recovery, the contribution of SE was evaluated to be equivalent or more compared to that of ARG in terms of tree density and species number in 2017. The large decrease of SE in their tree density (Table 2) was mostly attributed by pioneers (Table 1). This finding was consistent with Noguchi and Okuda (2012). It was reported that most of the pioneer species died during 5-11 years after clearcutting in a sugi plantation, but no change was observed in the number of species of evergreen broad-leaved trees. Density of lucidophyllous trees by SE were maintained as $60 \%$ of the initial value in the UI-plot, and rather increased by $16 \%$ in the UC-plot (Table 2). Thus, the decrease of SE density would not be serious in terms of the recovery of lucidophyllous trees as the major restoration target. Furthermore, species number of SE were larger than that of ARG in the both plots in the both censuses (the first year and 2017) (Table 3), demonstrating that the contribution of $\mathrm{SE}$ to the species number was larger than ARG over the mid-term recovery process. It is, however, suggested that this advantage of SE might be owing to the condition of the study site, where surrounding seed sources have been effectively existed. Actually, both the stands in the present study had adjacent seed sources, such as old coppices or old conifer plantation containing well developed understory or broadleaved trees coexisting in the canopy layer. The previous study conducted in the same region suggested the effective distance from the seed source as less than ca. $10-15 \mathrm{~m}$ for gravity-dispersal seed, while it exceeds $30 \mathrm{~m}$ for frugivorous-dispersal seeds (Yamagawa et al. 2010a, b). Thus, securing the surrounding seed source is critically important for expecting the significant role of SE equivalent to or more than ARG as shown in the present study.

Most of SE individuals are those of frugivore-dispersal types (Table 2). This was also true in 2017, but a slight increase of gravity-dispersal trees (which are lucidophyllous trees) was observed, indicating that SE contributed gradually to increase gravity-dispersal, lucidophyllous trees. However, their tree density by SE was still lower compared to that of ARG. These results suggested that the significance of SE to the recovery of gravity-dispersal, lucidophyllous trees was less than that of ARG as reported by the previous studies (Yamagawa and Ito 2006; Yamagawa et al. 2008), and still limited over a mid-term recovery process even under a condition supported by the effective seed source.

\section{Conclusions}

The results of this study revealed that, over a mid-term forest recovery, the cutting advance regenerations (ARs) at clearcutting resulted in increased R-AR in the UC-plot, which compensated the lack of S-AR together with individuals originated from newly established seedlings (SE). In other words, the advantage of AR retention was thought to be limited to the maintenance of tree population and stratification at the early stage of forest recovery. On the other hand, SE was found to have a large contribution than ARG to forest recovery in terms of tree density and species number, while its significance for the recovery of gravitydispersal, lucidophyllous trees was limited even for a midterm recovery process. Though the mid-term effect of AR retention was limited, the results indicated the importance of advance regeneration group (ARG) irrespective of cutting/retaining especially for gravity-dispersal-type species. Thus, it is suggested that accumulated advance regeneration 
is quite important for successful forest recovery, in particular for the cases, where securing the surrounding seed source is difficult. This study was conducted in the stands with relatively abundant understory vegetation and the surrounding seed source, and dealt with only large ARs $(\mathrm{DBH}>1 \mathrm{~cm})$. Thus, further studies using comparisons with stands with poorly developed understories before clearcutting and less effective seed sources are desired with evaluation of small advance seedlings.

Supplementary Information The online version contains supplementary material available at https://doi.org/10.1007/s11355-021-00485-4.

Acknowledgements We would like to thank the staff of the Tano Forest Science Station at the University of Miyazaki for their assistance during field surveys. The present study was supported in part by JSPS KAKENHI Grant Number 17K0786801, 25252029, 18K05749, 19H02997 and 21K18226.

Open Access This article is licensed under a Creative Commons Attribution 4.0 International License, which permits use, sharing, adaptation, distribution and reproduction in any medium or format, as long as you give appropriate credit to the original author(s) and the source, provide a link to the Creative Commons licence, and indicate if changes were made. The images or other third party material in this article are included in the article's Creative Commons licence, unless indicated otherwise in a credit line to the material. If material is not included in the article's Creative Commons licence and your intended use is not permitted by statutory regulation or exceeds the permitted use, you will need to obtain permission directly from the copyright holder. To view a copy of this licence, visit http://creativecommons.org/licenses/by/4.0/.

\section{References}

Brown DN, Curtis T, Adams CE (2015) Effect of clear-felling versus gradual removal of conifer trees on the survival of understory plants during the restoration of ancient woodlands. For Ecol Manag 348:15-22

Eycott AE, Watkinson AR, Dolman PM (2006) Ecological patterns of plant diversity in a plantation forest managed by clearfelling. $\mathrm{J}$ App Ecol 43:1160-1171

Hattori T, Minamiyama N, Hashimoto Y, Ishida H (2004) Flora of the lucidophyllous forest in Japan. Nat Hum Act 8:13-47

Hattori T, Tochimoto D, Minamiyama N, Hashimoto Y, Sawada Y, Ishida H (2009) Species richness and species composition of vascular epiphytes in the lucidophyllous forests in southern Kyushu. Veg Sci 26:49-61 (in Japanese)

Ito H, Ito S, Tsukamoto M, Nakao T (2008) Dynamics of multi-stem clump structure of canopy trees affects the change in stand structure of secondary lucidophyllous forests. J Jpn for Soc 90:46-54 (in Japanese with English abstract)

Ito S, Kizaki K, Mitsuda Y, Hirata R, Yamagawa H, Saegusa N (2013) Zoning of small catchment for restoration of natural forests with special reference to site productivity, soil erosion risks and riparian buffer strip. Landsc Ecol Mang 18(2):139-147 (in Japanese with English abstract)

Kitamura S, Murata G (1979) Colored illustrations of woody plants of Japan. Hoikusya, Osaka (in Japanese)

McLaren KP, McDonald MA (2003) Coppice regrowth in a disturbed tropical dry limestone forest in Jamaica. For Ecol Manag 180:99-111

Miyawaki A (1981) Vegetation of Japan-Kyushu. Shibundo, Tokyo (in Japanese)

Mogi T, Takahashi H, Katsuyama T (2000) Woody plants of Japan. Yama-kei Publishers, Tokyo (in Japanese)

Nagaike T (2000) A review of ecological studies on the effects of forest management on plant species diversity. J Jpn for Soc 82:407-416 (in Japanese with English abstract)

Noguchi M, Okuda S (2012) Changes in stand structure and species composition from 5 to 11 years after clear-cutting of a sugi plantation in the warm-temperate zone in Shikoku, Japan. J Jpn for Soc 94:192-195 (in Japanese with English abstract)

Okuda S (1997) Wild plants of Japan. Shougakukan, Tokyo (in Japanese)

Onaindia M, Ametzaga-Arregi I, Sebastian SM, Mitxelena A, Rodriguez-Loinaz G, Pena L, Alday GJ (2013) Can understory native woodland plant species regenerate under exotic pine plantations using natural succession? For Ecol Manag 308:136-144

R Core Team (2016) R: A language and environment for statistical computing. Vienna, (Austria) R Foundation for Statistical Computing. https://www.R-project.org/. Accessed 6 July 2021

Ramirez-Collio K, Vergara MP, Simonetti AJ (2017) Converting clear cutting into a less hostile habitat: the importance of understory for the abundance and movement of the Chestnut-throated HuetHuet (Pteroptochos cataneus: Rhinocryptidae). For Ecol Manag 384:279-286

Yamagawa H, Ito S (2006) The role of different sources of tree regeneration in the initial stages of natural forest recovery after logging of conifer plantation in a warm-temperate region. $\mathrm{J}$ for Res 11:455-460

Yamagawa H, Ito S, Nakao T (2008) Early establishment of broadleaved trees after logging of Cryptomeria japonica and Chamaecyparis obtusa plantations with different understory treatments. J for Res 13:372-379

Yamagawa H, Ikebuchi M, Ito S, Ito H, Hirata R (2010a) Acorn dispersal by wood mice in a secondary lucidophyllous forest on a steep slope in a warm-temperate region of Japan. J Jpn for Soc 92:157-161 (in Japanese with English abstract)

Yamagawa H, Ito S, Nakao T (2010b) Restoration of semi-natural forest after clearcutting of conifer plantations in Japan. Landsc Ecol Eng 6:109-117

Yamagawa H, Hioki Y, Kamada Y, Ito S (2013) Intention of the special issue "Methodology for reconfiguring semi-natural forests in plantation-dominated landscapes." Landsc Ecol Manag 18:79-81 (in Japanese)

Yoshida T (2019) Hojiboku ga syokusaiboku-koushin e ataeru eikyou [Effects of retained trees on planted and regenerated trees]. In: Kakizawa H, Yamaura Y, Kuriyama K (eds) Retention forestry. Tsukiji-shokan, Tokyo, pp 193-207 (in Japanese)

Zerbe S (2002) Restoration of natural broad-leaved woodland in Central Europe on sites with coniferous plantations. For Ecol Manag $167: 27-42$ 